Article

\title{
Development and Validation of a LC-MS/MS Method for Determination of Multi-Class Antibiotic Residues in Aquaculture and River Waters, and Photocatalytic Degradation of Antibiotics by $\mathrm{TiO}_{2}$ Nanomaterials
}

\author{
Tho Chau Minh Vinh Do ${ }^{1, *}$, Duy Quoc Nguyen ${ }^{1}$, Tuan Duc Nguyen ${ }^{2, *}$ and Phuoc Huu Le ${ }^{3, *}$ (1) \\ 1 Department of Drug Quality Control-Analytical Chemistry-Toxicology, Faculty of Pharmacy, Can Tho \\ University of Medicine and Pharmacy, 179 Nguyen Van Cu Street, Can Tho City 94000, Vietnam; \\ quocduyct.nguyen@gmail.com \\ 2 University of Medicine and Pharmacy at Ho Chi Minh City, 217 Hong Bang Street, District 5, \\ Ho Chi Minh City 760000, Vietnam \\ 3 Department of Physics and Biophysics, Faculty of Basic Sciences, Can Tho University of Medicine and \\ Pharmacy, 179 Nguyen Van Cu Street, Can Tho City 94000, Vietnam \\ * Correspondence: dcmvtho@ctump.edu.vn (T.C.M.V.D.); ductuan@ump.edu.vn (T.D.N.); \\ lhuuphuoc@ctump.edu.vn (P.H.L.)
}

Received: 3 March 2020; Accepted: 20 March 2020; Published: 24 March 2020

\begin{abstract}
This study presents a multi-residue method for simultaneous qualitative and quantitative analysis of eight antibiotics from some common classes, including beta-lactam, tetracyclines, lincosamides, glycopeptides, and sulfonamides in 39 aquaculture and river water samples from the Mekong Delta (Vietnam) using liquid chromatography-tandem mass spectrometry (LC-MS/MS). As a result, doxycycline (DXC), oxytetracycline (OTC), lincomycin (LCM), sulfamethoxazole (SMX), and sulfamethazine (SMZ) were detected with high frequency over $65 \%$ and an average concentration of $22.6-76.8 \mathrm{ng} \cdot \mathrm{mL}^{-1}$. The result suggests that antibiotic residues in the aquaculture and river waters are considered as an emerging environmental problem of the region. To address this issue, we fabricated the well-defined $\mathrm{TiO}_{2}$ nanotube arrays (TNAs) and nanowires on nanotube arrays (TNWs/TNAs) using the anodization method. The TNAs had an inner tube diameter of $\sim 95 \mathrm{~nm}$ and a wall thickness of $\sim 25 \mathrm{~nm}$. Meanwhile, the TNWs/TNAs had a layer of $\mathrm{TiO}_{2}$ nanowires with a length of $\sim 6 \mu \mathrm{m}$ partially covering the TNAs. In addition, both TNAs and TNWs/TNAs had pure anatase phase $\mathrm{TiO}_{2}$ with (101) and (112) dominant preferred orientations. Moreover, the TNAs and TNWs/TNAs effectively and rapidly degraded the antibiotic residues under UV-VIS irradiation at $120 \mathrm{~mW} / \mathrm{cm}^{2}$ and obtained over $95 \%$ removal at $20 \mathrm{~min}$. Indeed, the photocatalytic reaction rate constants $(k)$ were in the range of $0.14-0.36 \mathrm{~min}^{-1}$ for TNAs, and $0.15-0.38 \mathrm{~min}^{-1}$ for TNWs/TNAs. Noticeably, the $k$ values of TNWs/TNAs were slightly higher than those of TNAs for LCM, DXC, OTC, SMZ, and SMX that could be attributed to the larger surface area of TNWs/TNAs than TNAs when TNWs/TNAs had an additional $\sim 6 \mu \mathrm{m}$ TNWs top layer.
\end{abstract}

Keywords: liquid chromatography-tandem mass spectrometry; $\mathrm{TiO}_{2}$ nanomaterials; antibiotics; aquaculture wastewater; photocatalysts

\section{Introduction}

Antibiotics are widely used for treatment and prevention of infectious diseases in humans and in domestic and food-producing animals, including fish [1,2]. The use and overuse of antibiotics in aquaculture is of great concern because it may cause antibiotic residues in aquatic environments and 
potential ecosystem alteration. Extended exposure to low doses of antibiotics leads to the selective proliferation of resistant bacteria that could transfer the resistance genes to other bacterial species, and this causes a serious risk to the effectiveness of treatment of diseases, public health, and the eco-toxicological environment [3,4].

Antibiotic residue in an aquatic environment has been reported in recent studies through discharge from domestic sewer systems and environmental waters and wastewaters [5-10]. A nationwide survey conducted by the United States Geological Survey (USGS) Toxic Substances Hydrology Program [11] and the EU Water Framework Directive 2000/60/EC (WFD) [12] reported the presence of human and veterinary drugs in aquaculture and livestock products. This provides a framework for community action in the area of water policy for protection and management of inland waters, transitional waters, coastal waters, and groundwater.

Vietnam has faced alarming environmental problems, especially water pollution due to industrial development, urbanization, and rapid population growth. Rivers have been polluted with organic matter, nutrients, and bacteria due to untreated industrial effluents from many industries such as dyeing, paper mill, tanning, chemical manufacturing, fertilizer, plating, and food processing industries $[13,14]$. The Mekong Delta is the key agricultural production and aquaculture area of Vietnam. It comprises 13 provinces and covers an area of around $40,816 \mathrm{~km}^{2}$ with a total population of over 17.5 million. The annual average aquaculture output reached 400 thousand tons in 2018 [15]. However, antibiotics are increasingly used in aquaculture for the prevention and treatment of diseases. As a result, antibiotic residues in aquaculture wastewater of the Mekong Delta region (Vietnam) is considered an emerging environmental problem due to their adverse impacts on the ecology environment and human health [16,17].

An accurate quantification of pharmaceuticals at low concentrations in practical environmental samples is challenging due to the matrix complexity. Optimized methods using liquid chromatography-tandem mass spectrometry (LC-MS/MS) have been developed to analyze multi-residues of antibiotics in the aquatic environments, including beta-lactam [18-23], fluoroquinolones and macrolides [18,19,23-27], tetracyclines and sulfonamides [19,24,25,28-32], lincosamides [18,33], and phenicol [24,34]. Yet, few studies have been conducted on the analysis of antibiotic residues in aquaculture wastewater and river water samples. In addition, unlike the other high-risk popular pharmaceutical wastes such as sulfonamides antibiotics and fluoroquinolones [35-37], an analytical method for vancomycin has been little studied [23].

Multi-residue analytical methods using LC-MS/MS provide high sensitivity for studying the occurrence and fate of pharmaceuticals in the environment. However, simultaneous analysis of multiple classes of antibiotics with different physicochemical properties in matrix samples is a great challenge, which calls for systematic studies to develop the optimized analytical LC-MS/MS method. It is worth mentioning that a solid-phase extraction (SPE) pre-treatment technique has been developed, and it allows for automation and reducing the consumed volume of organic solvents and the analysis time [18-20,23-28,31,32,38,39].

The conventional wastewater treatment plants are not designed to treat water polluted with pharmaceuticals and stable organics, and thus, the applied treatments are ineffective in their removal [40-45]. In recent years, advanced oxidation processes (AOPs) are recommended when water pollutants have high chemical stability. AOPs allow almost total mineralization of contaminants to carbon dioxide, water, and inorganic compounds to be achieved or, at least, allow their partial oxidation to become more biodegradable and/or less harmful [46,47]. Notably, in some cases, oxidated products can be more toxic than their parent compounds [48-53]. Semiconductor photocatalysis has been recognized as one of the most promising technologies to decontaminate organics and pharmaceuticals [54-56]. AOPs are characterized by the formation of the highly reactive ${ }^{\bullet} \mathrm{OH}$ and $\mathrm{h}^{+}$ under UV/VIS irradiation in water, which can degrade different pollutants [47,57-59].

Titanium dioxide $\left(\mathrm{TiO}_{2}\right)$ has been widely used as a photocatalyst in the treatment of organic and pharmaceutical wastewaters because of its excellent photocatalytic activity, wide availability 
and non-toxicity $[46,47,60-64]$. In this study, $\mathrm{TiO}_{2}$ nanotube arrays (TNAs) and $\mathrm{TiO}_{2}$ nanowires on nanotube arrays (TNWs/TNAs) are of interest because they can provide a large surface-to-volume ratio and unidirectional electrical channel $[65,66]$. TNWs/TNAs presented better photocatalytic activity in degradation of methylene blue than that of TNAs, which was attributed to the presence of partial coverage of TNWs on the surface of TNAs for the enhanced surface area [67]. By using anodic oxidation, TNAs and TNWs/TNAs can be fabricated on immobilized titanium folds that allow the photocatalysts from the reaction solution to be retrieved after treatment, which can then be reused many times.

In this work, we firstly developed a multi-residue analytical LC-MS/MS method for the simultaneous determination of eight antibiotics from five common classes in aquaculture and river water samples. The target antibiotics were selected based on high human consumption, ecotoxicology relevance, and popular veterinary antibiotics, including beta-lactams (amoxicillin, ampicillin), tetracyclines (oxytetracycline, doxycycline), sulfonamides (sulfamethoxazole, sulfamethazine), lincosamides (lincomycin), and glycopeptide (vancomycin). Then, the developed method was applied to determine antibiotic residues in 39 wastewater samples from four large-scale aquaculture areas in the Mekong Delta, Vietnam. Finally, photocatalytic degradation of antibiotic residues by TNAs and TNWs/TNAs under UV-VIS irradiation were studied. As a result, TNAs and TNWs/TNAs presented as effective nanomaterials to remove antibiotic residues in practical aquaculture and river waters.

\section{Results and Discussion}

\subsection{Optimal MS/MS Parameters}

For all target compounds, we used ESI source with nitrogen as the nebulizer and drying gas, in positive ion mode operation, with a capillary voltage of $3.0 \mathrm{kV}$ and temperature source of $150{ }^{\circ} \mathrm{C}$. Nitrogen was used as a sheath gas at a flow rate of $950(\mathrm{~L} / \mathrm{h})$. The desolvation temperature was 400 ${ }^{\circ} \mathrm{C}$, and argon gas was used to induce dissociation for the acquisition of MS/MS data. Individual tune files were created for each standard in continuous flow mode to determine the optimum cone voltages, collision energies, isolation widths, and fragment ions, which are listed in Table 1 [see also Figures S1-S10 in supplementary materials (SM)].

Table 1. Summary of the retention times and MS/MS parameters, precursors, and products observed for eight target antibiotics and two internal standards.

\begin{tabular}{|c|c|c|c|c|c|c|c|}
\hline Compounds & $\begin{array}{l}\text { Retention } \\
\text { Time }\end{array}$ & $\begin{array}{l}\text { Precusor Ion } \\
\qquad[\mathrm{M}+\mathrm{H}]^{+}\end{array}$ & $\begin{array}{l}\text { Product Ion } 1 \\
\text { (Quantitative) }\end{array}$ & $\begin{array}{c}\text { Product Ion } 2 \\
\text { (Identified) }\end{array}$ & $\begin{array}{c}\text { Cone } \\
\text { Voltage } \\
\text { (V) }\end{array}$ & $\begin{array}{c}\text { Optimal } \\
\text { Collision } \\
\text { Energy-Product } \\
\text { Ion } 1(\mathrm{~V})\end{array}$ & $\begin{array}{c}\text { Optimal } \\
\text { Collision } \\
\text { Energy-Product } \\
\text { Ion } 2(\mathrm{~V})\end{array}$ \\
\hline Ampicillin & 4.55 & 350.3 & 106.1 & 114 & 28 & 20 & 30 \\
\hline Oxy tetracycline & 5.33 & 461 & 426.1 & 443 & 34 & 20 & 12 \\
\hline Doxycycline & 8.43 & 445.3 & 428 & 98.1 & 38 & 16 & 44 \\
\hline Sulfamethoxazole & 8.06 & 254.2 & 92.1 & 108 & 28 & 28 & 24 \\
\hline Sulfamethazine & 6.43 & 279.2 & 186 & 92 & 38 & 16 & 30 \\
\hline Trimethoprim (IS-1) & 4.81 & 291.3 & 123.1 & 230.1 & 48 & 24 & 24 \\
\hline Atenolol (IS-2) & 3.83 & 267.4 & 56.1 & 71.6 & 38 & 28 & 22 \\
\hline
\end{tabular}

The structure of the analytes contained nitrogen and had small molecular weight with median polarity, whereby ionization of the positive ion mode for all target compounds was selected to increase the sensitivity when compared with the negative ion mode. For quantitative analysis, most of the investigated antibiotics presented MRM transitions in between the precursor ion and the two most abundant fragment ions. Only one obtained transition with high intensity was reliable for quantification, while the full scan MS/MS and daughter scan data were used for structural confirmation of the target compounds. Consequently, the obtained parent and fragment ions, particularly quantitative product fragments of the target compounds merged intensively with European MassBank data [68] and 
the other relevant results $[18,19,23-26,28,31,32,69-71]$. This provides further support for the broad accomplishment of the requirements set by the EU Commission Decision 2002/657/EC about the identification and confirmation of pharmaceuticals in LC-MS/MS analysis.

In this study, trimethoprim (TMTP) was used as an internal standard for sulfonamide, beta-lactam, tetracycline, and lincosamide classes [70]. TMTP (an antibiotic) still can be used as an internal standard because its concentration in the aquaculture and livestock waters of the Mekong Delta region was ultralow or not detected [35-37,72]. Atenolol was used as an internal standard for glycopeptide group, suggested by the earlier study [73]. It is found that both TMTP and atenolol have high physicochemical stability, and they offer a high, stable, and repeatable relative abundance of precursor ions $(2.04 \times$ $\left.10^{8}-3.62 \times 10^{8}\right)$ and product ions $\left(3.79 \times 10^{7}-5.05 \times 10^{7}\right)$.

To avoid reducing the sensitivity, the elevated number of transitions were recorded in one retention time window by setting the appropriate values of the dwell-time and pause between mass ranges. It is worth mentioning that selection of an appropriate dwell time is a key factor to monitor a large number of transitions in the same time segment and to obtain enough points per chromatographic peak $(>15$ points), which is very important for precise quantification. For example, the signal intensity of OTC, AMP, and AMOX increased significantly when dwell-time was adjusted from 0.025 to 0.05 . It means that the detector can devote more time to monitoring every transition in each cycle.

Dissolved solvent also strongly affects the ionization of target compounds in a MS analysis. Generally, water and methanol result in better performance than acetonitrile (ACN) for most antibiotics. We found that formic acid addition $(0.1 \%)$ to the aqueous phase resulted in a significant improvement in peak shape and intensity for AMP, AMOX, VCM, LCM, SMZ, and SMX in positive ion mode (Figures S11-S14 in SM).

\subsection{Chromatographic Optimization}

The stationary phase plays an important role in separation efficiency. Hence, three types of analytical columns were studied, namely Agilent Poroshell 120 Phenyl-Hexyl $(4.6 \mathrm{~mm} \times 150 \mathrm{~mm} \times$ $2.7 \mu \mathrm{m})$, Agilent Eclipse Plus C18 $(4.6 \times 150 \mathrm{~mm} ; 3.5 \mu \mathrm{m})$, and Phenomenex Lunar C8 $(4.6 \times 250 \mathrm{~mm}$; $5 \mu \mathrm{m})$. As a result, the first column offered a better separation, apparent peak shape and signal, and short analysis time $(<10 \mathrm{~min})$. This result indicates that the phenyl and hexyl structures are suitable for the separation of antibiotic samples with acid, medium polarity, and a small particle size of $\sim 2.7 \mu \mathrm{m}$.

The most common mobile phases for antibiotic residue studies using LC-MS/MS are methanol and/or acetonitrile-water, and formic acid is often added at low levels to facilitate ionization by ensuring the analyte is more basic than the solvent [19-22,24-26,28-32,69-71]. Herein, the mobile phase of methanol-water with/without adding formic acid at various concentrations of $0.01,0.05,0.1,0.15$, and $0.2 \%$ was studied. We found that the optimal concentration of formic acid was $0.1 \%(\mathrm{pH}=2.33)$ owing to the results of the improved separation, good peak shape, and high signal intensity for most of the investigated compounds. Furthermore, a small portion of acetonitrile added to the mobile phase led to a reduced analysis time and the changed compound partition to improved resolution for most analytes. However, co-eluting peaks occurred for AMOX and LCM. Therefore, a gradient elution of methanol-acetonitrile-water with $0.1 \%$ formic acid provided the best resolution and peak symmetry for analyzing all the target antibiotics. It was found that the other parameters of flow rate, injected volume, and temperature column could only change the separation time, but they did not noticeably improve the resolution of peaks (Figures S15-S21 in SM). In summary, the optimum chromatographic conditions were the usage of a Poroshell 120 Phenyl-Hexyl column $(4.6 \times 150 \mathrm{~mm} ; 2.7 \mu \mathrm{m}$; Agilent, USA), $400 \mu \mathrm{L} / \mathrm{min}$ flow rate, and the full loop injection volume of $10 \mu \mathrm{L}$. The separation was achieved by using a ternary gradient mobile phase consisting of $\mathrm{ACN}(\mathrm{A}), \mathrm{MeOH}(\mathrm{B})$, and water with $0.1 \%$ formic acid (C). The total required time for the chromatographic analysis was $20 \mathrm{~min}$, which was comparable or shorter than the time spent of $20-40 \mathrm{~min}$ in $[27,31,32]$. The optimal conditions are listed in Table 2 and presented in Figure 1. 
Table 2. Summary of the mobile-phase compositions for the chromatographic separation. A, B, C are $\mathrm{ACN}, \mathrm{MeOH}$, and water with $0.1 \%$ formic acid, respectively.

\begin{tabular}{cccc}
\hline Time (minutes) & $\mathbf{\% A}$ & $\mathbf{\% B}$ & $\mathbf{\% C}$ \\
\hline 0 & 24 & 13 & 63 \\
5.3 & 24 & 13 & 63 \\
5.8 & 5 & 94 & 1 \\
10.5 & 5 & 94 & 1 \\
11 & 24 & 13 & 63 \\
15 & 24 & 13 & 63 \\
\hline
\end{tabular}

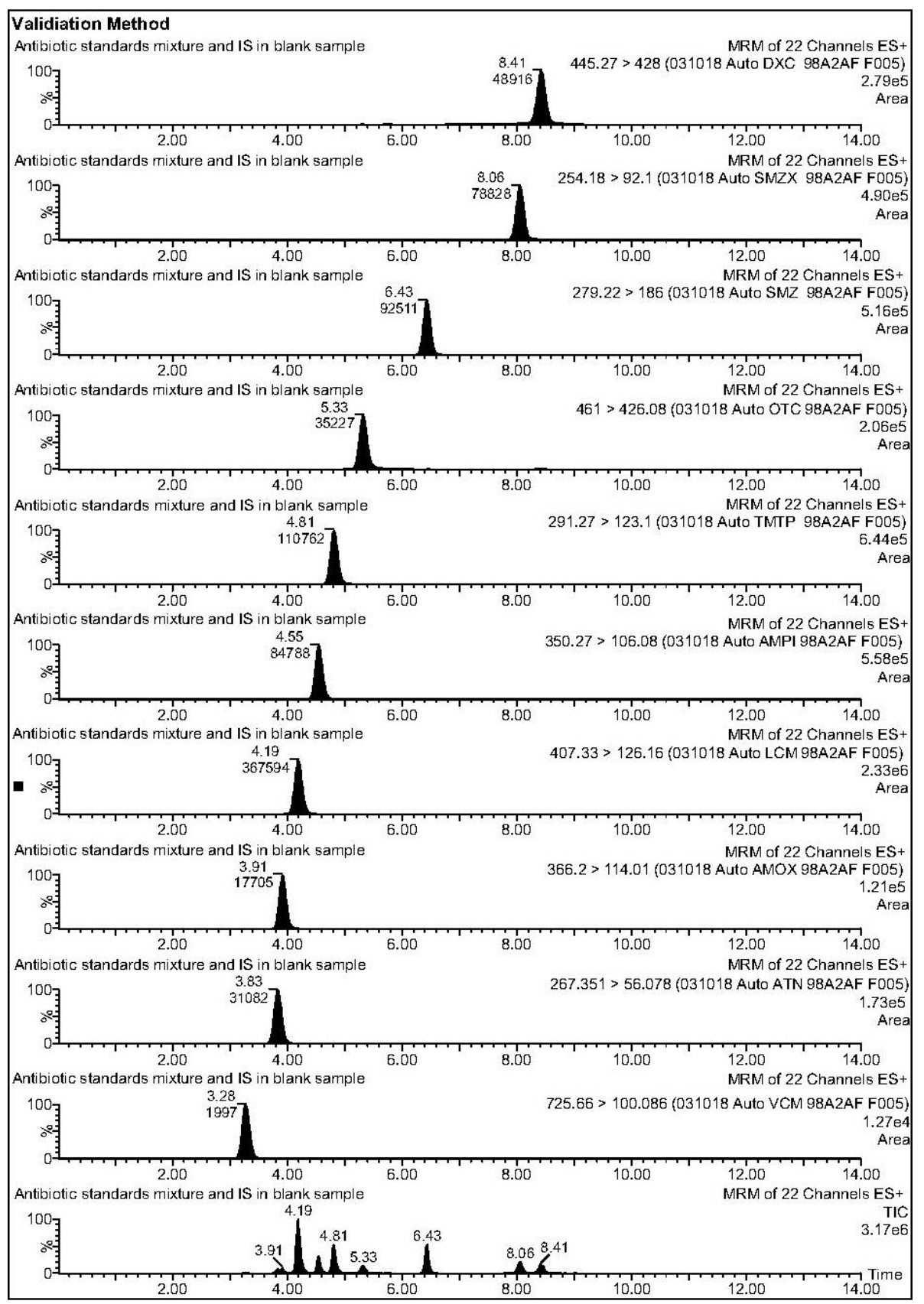

Figure 1. The obtained chromatogram for the separation of a mixture of eight standard antibiotics $\left(100 \mathrm{ng} \cdot \mathrm{mL}^{-1}\right)$ and internal standards $\left(100 \mathrm{ng} \cdot \mathrm{mL}^{-1}\right)$ in blank wastewater samples at the optimum mass parameters and chromatographic conditions. 


\subsection{Optimization of Sample Preparation}

As shown in Figure 2, when the water samples were only filtered through 1- $\mu \mathrm{m}$ glass fiber and $0.45-\mu \mathrm{m}$ nylon membrane filters, poor recovery yields $(<50 \%)$ were observed for most of the antibiotics. Furthermore, the baseline noise was very high $\left(\times 10^{4}\right)$ due to the presence of suspended solids. Meanwhile, the first extraction process with an addition of $0.3 \mathrm{~g} \mathrm{Na}_{2}$ EDTA was the best for significant improvement in recovery efficiencies $(81.8-114.6 \%)$ as well as reducing dramatically the baseline noise to $2 \times 10^{2}$ for all the target compounds. These results met compliance requirements and were consistent with the experimental results in $[19,24,25,28-30,69-72,74]$, in which the extraction recoveries were enhanced when $\mathrm{Na}_{2}$ EDTA was used as a chelating agent to form complexes with inorganic elements and to bind the residual metals in the sample matrix and glassware. For the second procedure, Strata-X cartridges offered high extraction yields for AMOX, AMPI, OTC, VCM, LCM (i.e., 87.5-102.5\%). However, it gave poor extraction yields for DXC, SMZ, and SMX (5.7-25\%) because of the strong retention of neutral- and medium-polar compounds of Strata-X as it is a reverse-phase functionalized polymeric sorbent. The use of HLB-SPE resulted in high recovery yields in the range of $84.6-109.2 \%$ owing to the balance between the hydrophilic N-vinyl pyrollidone and lipophilic divinyl benzene that provided a superior reversed-phase capacity and a retention enhancement for polar analytes. However, it required a longer sample treatment time (30 $\mathrm{min} / \mathrm{sample})$. For the third process, prior to use of Strata-X or HLB cartridges, an addition of $0.3 \% \mathrm{Na}_{2}$ EDTA reduced the matrix effects and slightly enhanced the recovery yields. Indeed, the third procedure offered high recovery yields for all the antibiotics (89.3-107.4\%), whose results were comparable to previous works [19-21,23-25,27-30,70,72,74,75], but it required a long sample preparation time of $40 \mathrm{~min} / \mathrm{sample}$. Briefly, higher cost and longer sample preparation time were the main drawbacks of the second and the third procedures, compared to the first process, which had a short preparation time of $10 \mathrm{~min} / \mathrm{sample}$ and was $60 \%$ cheaper (Figures S22-S25 in SM).

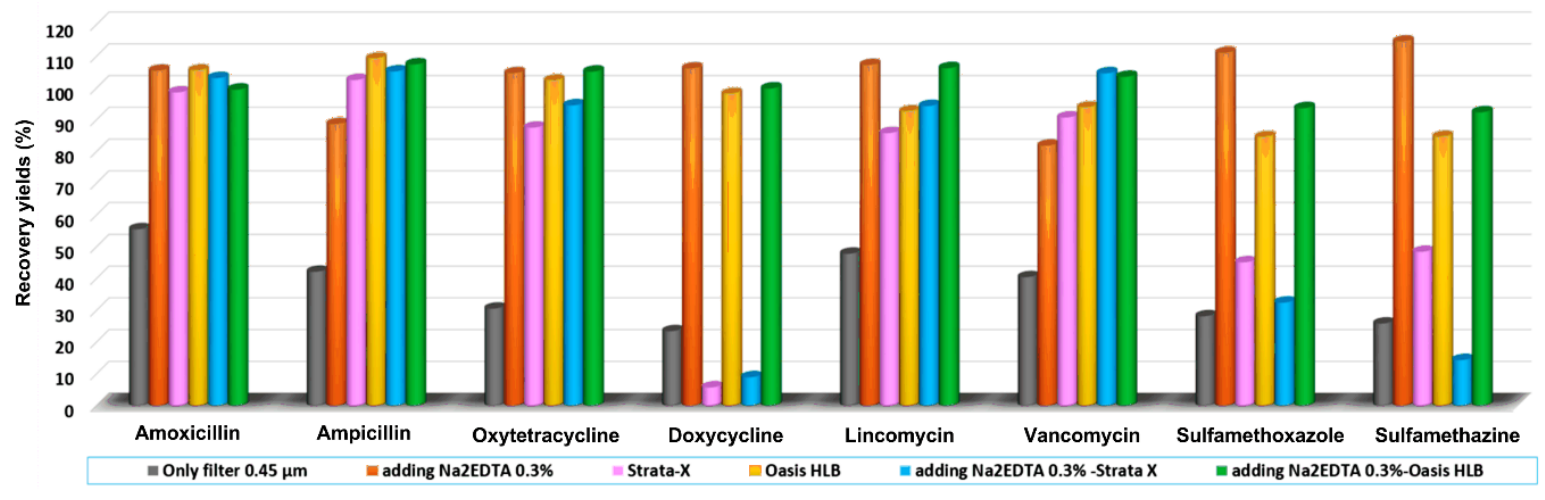

Figure 2. Extraction recoveries of target antibiotics at different extracted conditions.

\subsection{Matrix Effects}

Suppression or enhancement ions occur frequently during LC-MS/MS analysis due to the ionization competition between co-eluting compounds in a chromatographic system. Particularly, for a complex environment and bio-samples, the percentage of the suppression may depend on the structures of the compounds and matrix samples. In this study, the deviation of the matrix effects for most antibiotics were far higher than the required value of $20 \%[19,24,25,28,31]$, and thus, the quantitative analysis based on a pure standard solution curve was not appropriate. It would be an ideal approach to have internal standards for each class of antibiotics to compensate for matrix effects in the multi-component analysis, but this leads to a rise in the cost of labeled reference materials. Alternatively, this study developed calibration curves for detection of the target compounds using a linear regression analysis by adding a series of standard solutions to the matrix solution. Indeed, TMTP was used as an internal 
standard for beta-lactam, tetracycline, lincosamide, sulfonamide classes, while atenolol was used for vancomycin.

\subsection{Method Validation}

Method optimization was indicated by its validation. We determined all the validation parameters of specificity, sensitivity, linearity, precision, and accuracy, whose results are shown in Table 3 (see also Figures S26-S36 in SM).

Table 3. Validation parameters for the developed LC-MS/MS method. The linearity range was 0.05-200 $\mathrm{ng} / \mathrm{mL}$. The antibiotic abbreviations: AMOX, amoxicillin; AMPI, ampicillin; OTC, oxytetracycline; DXC, doxycycline, LCM, lincomycin; VCM, vancomycin; SMZ, sulfamethazine; and SMX, sulfamethoxazole.

\begin{tabular}{ccccccccc}
\hline Parameter & AMOX & AMPI & OTC & DXC & LCM & VCM & SMZ & SMX \\
\hline $\mathrm{r}^{2}$ & 0.998 & 0.998 & 0.998 & 0.995 & 0.999 & 0.995 & 0.999 & 0.997 \\
MDLs (ng.mL $^{-1}$ ) & 0.05 & 0.02 & 0.02 & 0.05 & 0.025 & 0.07 & 0.025 & 0.01 \\
MQLs (ng.mL $^{-1}$ ) & 0.16 & 0.07 & 0.05 & 0.15 & 0.06 & 0.20 & 0.07 & 0.03 \\
Precision $^{\mathrm{a}}$ (intra-day) & 3.70 & 3.10 & 4.11 & 2.82 & 1.14 & 4.21 & 3.08 & 1.96 \\
Precision $^{\mathrm{b}}($ inter-day) & 4.73 & 3.94 & 4.30 & 3.48 & 1.60 & 4.11 & 4.61 & 3.70 \\
\hline Accuracy $^{\mathrm{c}}\left(40 \mathrm{ng} \cdot \mathrm{mL}^{-1}\right)$ & 87.36 & 87.04 & 96.35 & 96.51 & 100.47 & 91.57 & 105.6 & 101.24 \\
Accuracy $^{\mathrm{c}}\left(20 \mathrm{ng} \cdot \mathrm{mL}^{-1}\right)$ & 89.51 & 89.06 & 94.36 & 90.28 & 99.77 & 88.87 & 103.45 & 99.81 \\
Accuracy $^{\mathrm{c}}\left(10 \mathrm{ng} \cdot \mathrm{mL}^{-1}\right)$ & 88.65 & 87.67 & 92.33 & 89.75 & 98.99 & 87.03 & 101.68 & 100.24 \\
\hline
\end{tabular}

${ }^{a}$ Maximum deviation within one day based on peak area in percent $(n=9)$; ${ }^{b}$ deviation over three days based on peak area in percent $(n=3) ;{ }^{c}$ expressed as recovery rates in percent.

It is well-known that specificity was assured by the identification and confirmation criteria for the analysis of target substances based on the European Commission Decision 2002/657/EC [76]. For the confirmation of the presence of antibiotics, a minimum of four identification points (IPs) is required [76]. When using the SRM approach, four IPs can be collected by obtaining two MRM transitions with 1.5 IPs each and 1.0 IPs for the precursor. Particularly, the RSD percentages of retention time for all the investigated antibiotics were less than $0.1 \%$ ( $2.5 \%$ tolerance), and the relative intensity difference between the two transitions was less than $20 \%$. Furthermore, the selectivity of the method was evaluated by comparing the chromatograms obtained from the standard, spiked blank analyte samples with those obtained from the blank samples. There were no significant interference peaks of the analytes and internal standards at the retention times.

The quantitative analysis shows excellent linear behavior with $\mathrm{r}^{2} \geq 0.995$ and a wide dynamic range of $0.05-200 \mathrm{ng} \cdot \mathrm{mL}^{-1}$. For the sensitivity, MDLs and MQLs of target antibiotics were in the range of $0.01-0.07 \mathrm{ng} \cdot \mathrm{mL}^{-1}$ and $0.03-0.20 \mathrm{ng} \cdot \mathrm{mL}^{-1}$, respectively, whose values were reasonable and typical for triple quadrupoles mass detector analysis. The assay accuracy was determined from the recovery experiments at three concentration levels within the dynamic range, as the matrix was spiked before treatment. The obtained recovery rates were in the range of $87.03-105.6 \%$ (tolerance of $80-110 \%$ ) [76], indicating that the sample preparation procedure gave excellent integrity. Thanks to the precision level, the maximum relative standard deviation was as low as $4.73 \%$ for AMOX, which was far lower than the value of $15 \%$ of the criteria. The developed method passed all the validation requirements, and thus, this method is appropriate for analyzing antibiotics in practical water samples.

\subsection{Evaluation of the Antibiotic Residues in Aquaculture and River Water Samples}

The validated method was applied to assess 39 wastewater samples, collected from the four large-scale aquaculture areas and four rivers/canals in the Mekong Delta, Vietnam. Table 4 summarizes the occurrence and concentration of antibiotics detected in the aquaculture wastewater samples. Clearly, all the eight antibiotics were detected in the samples collected in Dam Doi and Hoa Binh districts. It is suggested that these places are amongst the largest aquaculture production areas in the Mekong Delta with high demands of antibiotic usage. Among of the eight antibiotics, OTC and SMX were 
found in all wastewater samples; and DXC, LCM, and SMZ were detected frequently with $65.7 \%$, $68.6 \%, 74.3 \%$, respectively. Moreover, OTC was found at the highest average level $\left(76.8 \mathrm{ng} \cdot \mathrm{mL}^{-1}\right)$, followed by SMX $\left(60.9 \mathrm{ng} \cdot \mathrm{mL}^{-1}\right), \mathrm{LCM}\left(32.5 \mathrm{ng} \cdot \mathrm{mL}^{-1}\right), \mathrm{SMZ}\left(24.6 \mathrm{ng} \cdot \mathrm{mL}^{-1}\right)$, and DXC $\left(27.5 \mathrm{ng} \cdot \mathrm{mL}^{-1}\right)$. Meanwhile, AMPI and AMOX were detected at low concentrations in the aquaculture wastewater samples. The higher detection rates and concentrations of the former antibiotics are probably due to their wide range of disease prevention and treatment in aquaculture and their lower prices than those of the latter antibiotics. Noticeably, VCM has been banned for use in aquaculture, but it was found at a high rate of $25.7 \%(9 / 35)$, even at low average levels $\left(1.1-5.7 \mathrm{ng} \cdot \mathrm{mL}^{-1}\right)$. VCM could come from the feeding products in aquaculture, and it could lead to unsafe aquaculture products. The river/canal water samples collected near pangasius and shrimp farms contained OTC, SMX, DXC, SMZ, and LCM at low levels of $1.1,0.8,0.4,0.3$, and $0.3 \mathrm{ng} \cdot \mathrm{mL}^{-1}$, respectively, while VCM was not detected (Table 5). This is because of the spread of the antibiotics from aquaculture wastewater sources (Figures S37-S41 in SM).

Table 4. Occurrence and concentration $\left(n=3, \mathrm{ng} \cdot \mathrm{mL}^{-1}\right)$ of antibiotics detected in aquaculture farm wastewater samples in four different areas in Mekong Delta, Vietnam.

\begin{tabular}{|c|c|c|c|c|c|c|c|c|c|c|c|c|}
\hline \multirow{2}{*}{ Antibiotics } & \multicolumn{3}{|c|}{ CM-DD ${ }^{1-10}$} & \multicolumn{3}{|c|}{ BL-HB $^{1-10}$} & \multicolumn{3}{|c|}{$\mathrm{CT}^{-T^{2}}{ }^{1-6}$} & \multicolumn{3}{|c|}{$A G-C T^{1-9}$} \\
\hline & $\mathrm{Occ}^{\mathrm{a}}$ & Range & Aver $^{b}$ & Occ & Range & Aver & Occ & Range & Aver & Occ & Range & Aver \\
\hline AMOX & $1 / 10$ & 0.4 & 0.4 & $2 / 10$ & $0.3-0.8$ & 0.55 & n.d ${ }^{c}$ & n.d & n.d & n.d & n.d & n.d \\
\hline AMPI & $2 / 10$ & $0.1-0.3$ & 0.2 & $3 / 10$ & $0.3-0.7$ & 0.6 & n.d & n.d & n.d & n.d & n.d & n.d \\
\hline DXC & $7 / 10$ & $1.7-12.6$ & 6.2 & $6 / 10$ & $1.5-8.9$ & 7.1 & $4 / 6$ & $1.4-7.6$ & 4.8 & $6 / 9$ & $7.3-55.6$ & 27.5 \\
\hline OTC & $10 / 10$ & $12-112.6$ & 76.8 & $10 / 10$ & $6.2-25.4$ & 14.3 & $6 / 6$ & $2.3-27.4$ & 18.5 & $9 / 9$ & $0.7-2.7$ & 1.7 \\
\hline LCM & $7 / 10$ & $5.2-22.6$ & 16.5 & $7 / 10$ & $9.8-60.7$ & 32.5 & $4 / 6$ & $0.3-1.4$ & 0.9 & $6 / 9$ & $2.4-25.2$ & 13.3 \\
\hline VCM & $3 / 10$ & $1.7-4.8$ & 3.0 & $4 / 10$ & $1.1-5.7$ & 3.7 & n.d & n.d & n.d & $2 / 9$ & $1.6-5.2$ & 3.4 \\
\hline SMX & $10 / 10$ & $18.6-83.5$ & 60.9 & $10 / 10$ & $3.2-25.8$ & 16.5 & $6 / 6$ & $0.4-12.2$ & 7.6 & $9 / 9$ & $2.4-23.6$ & 11.5 \\
\hline SMZ & $7 / 10$ & $6.8-20.5$ & 10.4 & $8 / 10$ & $1.1-15.5$ & 8.7 & $4 / 6$ & $1.6-10.8$ & 6.5 & $7 / 9$ & $7.2-48.4$ & 24.6 \\
\hline
\end{tabular}

Table 5. Concentration $\left(n=3, \mathrm{ng} \cdot \mathrm{mL}^{-1}\right)$ of antibiotics determined in river/canal water samples.

\begin{tabular}{ccccc}
\hline \multirow{2}{*}{ Antibiotics } & \multicolumn{4}{c}{ Levels $\mathbf{( n g} \cdot \mathbf{m L}^{-\mathbf{1}}$ ) } \\
\cline { 2 - 5 } & DD-River & BL-River & XS-Canal & BT-Canal \\
\hline AMOX & n.d & n.d & n.d & n.d \\
AMPI & n.d & n.d & n.d & n.d \\
DXC & 0.2 & 0.3 & 0.2 & 0.4 \\
OTC & 1.1 & 0.1 & 0.2 & n.d \\
LCM & 0.1 & 0.3 & n.d & 0.1 \\
VCM & n.d & n.d & n.d & n.d \\
SMX & 0.8 & 0.3 & n.d & 0.1 \\
SMZ & 0.2 & 0.1 & 0.2 & 0.3 \\
\hline
\end{tabular}

Managaki et al. [35] reported the occurrence of SMZ (a veterinary medicine) with high concentrations of 19,200 and 18,500 ng/L in pig farm wastewater samples at many locations in Vietnam. Shimizu et al. (2013) [72] reported that OTC was predominant in livestock wastewater, and its concentration was $175 \mathrm{ng} / \mathrm{L}$ in pig farm effluents. In addition, the average concentration of SMX in sewage water was $1720 \mathrm{ng} / \mathrm{L}$ in Vietnam. In many cases, SMZ and LCM were predominant in livestock and aquaculture wastewater. Moreover, the concentrations of SMX in surface- and bottom-layer shrimp ponds and shrimp pond water samples in aquatic system of Vietnam were 40-2390, 40-5570 and 4.77-820 $\mu \mathrm{g} / \mathrm{L}$, respectively [77]. Tong et al. (2009) [75] reported the presence of sulfonamides and tetracyclines in swine wastewater and environmental water samples in central China, at levels of 5.8-21692.7 ng/L and 1.6-11.6 ng/L, respectively. Shao et al. (2009) [24] indicated that OTC could be 
measured in slaughterhouse wastewater samples collected from Beijing, with concentration ranging from 95 to $2942 \mathrm{ng} / \mathrm{L}$. OTC with concentrations of $25-410 \mu \mathrm{g} / \mathrm{L}$ was also detected in swine waste storage lagoons samples, while SMZ was found at a concentration range of 2.5-400 $\mu \mathrm{g} / \mathrm{L}$ [74]. Furthermore, OTC $(1.0-2.0 \mu \mathrm{g} / \mathrm{L})$ and SMZ $(0.3 \mu \mathrm{g} / \mathrm{L})$ were detected in surface water samples collected proximal to the swine and poultry farms [74]. Watkinson et al. (2007) [18] presented that amoxicillin was not detected in sewage in some recent surveys in Germany and Sweden because beta-lactams are easily transformed through hydrolysis by the unstable beta-lactam ring. In this study, we found comparable residue levels of SMX, SMZ, OTC, AMOX, and AMPI as compared with the aforementioned results in the literature. It is suggested that sulfonamide and tetracycline classes were frequently prescribed in aquaculture and livestock usage. Besides, this study also illustrated that the use of LCM has increased substantially in recent years. Notably, a banned antibiotic of VCM were detected in the aquaculture wastewater with high frequent occurrence and low concentration.

\subsection{Photocatalytic Degradation of Antibiotics in Aquaculture Wastewater Samples by $\mathrm{TiO}_{2} \mathrm{Nanomaterials}$}

Antibiotic residue in aquaculture wastewater is a very concerning environmental issue in the Mekong Delta, Vietnam. In order to contribute to tackling this issue, we studied the photocatalytic degradation of five antibiotics using $\mathrm{TiO}_{2}$ nanomaterials (i.e., TNAs and TNWs/TNAs) under UV-VIS irradiation at $120 \mathrm{~mW} . \mathrm{cm}^{-2}$. The TNAs and TNWs/TNAs exhibited well-defined nanostructures (Figure 3a,b). Indeed, the TNAs had an inner tube diameter of $\sim 95 \mathrm{~nm}$ and a wall thickness of $\sim 25$ $\mathrm{nm}$ (Figure 4a). Meanwhile, the TNWs/TNAs had a layer of $\mathrm{TiO}_{2}$ nanowires with a length of $\sim 6 \mu \mathrm{m}$ covering the TNAs (Figure 3b). The EDS analysis shown in Figure $3 \mathrm{c}$ revealed the presence of dominant elements of $\mathrm{Ti}$ (32-33 at.\%) and $\mathrm{O}$ (67-68 at.\%), which corresponded to the close-stoichiometry of the $\mathrm{TiO}_{2}$ phase. Notably, small Pt peaks appeared in the EDS spectra because the samples were coated with a thin layer of $\mathrm{Pt}$ to make them conductive for the SEM measurements. In addition, both TNAs and TNWs/TNAs had a pure anatase phase with (101) and (112) dominant preferred orientations (Figure 3d). By using the Scherer formula for the (101) peak [78], the calculated grain sizes of the TNAs and TNWs/TNAs were $32.8 \mathrm{~nm}$ and $27.3 \mathrm{~nm}$, respectively.

We selected the aquaculture wastewater samples with high antibiotic concentrations, including OTC (CM-DD $\left.{ }^{5}, 112.6 \mathrm{ng} \cdot \mathrm{mL}^{-1}\right)$, DXC (AG-CT $\left.{ }^{8}, 55.6 \mathrm{ng} \cdot \mathrm{mL}^{-1}\right), \mathrm{SMX}\left(\mathrm{CM}-\mathrm{DD}^{9}, 83.5 \mathrm{ng} \cdot \mathrm{mL}^{-1}\right), \mathrm{SMZ}$ $\left(\mathrm{AG}-\mathrm{CT}^{2}, 48.4 \mathrm{ng} \cdot \mathrm{mL}^{-1}\right)$, and LCM (BL-HB $\left.{ }^{4}, 60.7 \mathrm{ng} \cdot \mathrm{mL}^{-1}\right)$ to study photocatalytic degradation of the antibiotics by TNAs and TNWs/TNAs under UV-VIS exposure at various reaction times of 0,5, 9, 14, and $20 \mathrm{~min}$. The pseudo-first-order rate constants were determined by fitting the data with the Langmuir-Hinshelwood kinetics rate model $[63,79]$. Figure 4a,b show the photocatalytic degradation kinetic of LCM, DXC, OTC, SMZ, and SMX using TNAs and TNWs/TNAs under UV-VIS irradiation. Clearly, both photolysis and photocatalysis reactions generally follow the exponential decay, $\mathrm{C}_{\mathrm{t}}=\mathrm{C}_{0}$ $\times \mathrm{e}^{-\mathrm{kt}}$, where $C_{t}$ is the concentration of antibiotic at time $\mathrm{t}(\mathrm{ng} / \mathrm{mL}), \mathrm{C}_{0}$ is the initial concentration of antibiotic $(\mathrm{ng} / \mathrm{mL})$, and $\mathrm{k}$ is the reaction rate constant $\left(\mathrm{min}^{-1}\right)$. The $\mathrm{k}$ is yielded by performing the linear fitting on the plot of $-\ln \left(C_{t} / C_{0}\right)$ versus reaction time $t$, and they are shown in Figure $4 d$.

Generally, all the antibiotics absorb light in the UV range, as shown in Figure 4c. The antibiotics also degrade under photolysis of UV-VIS illumination at $120 \mathrm{~mW} / \mathrm{cm}^{2}$. However, with the presence of TNAs or TNWs/TNAs, the $\mathrm{k}$ value of photocatalysis is remarkably higher than that of photolysis (Figure $4 \mathrm{a}, \mathrm{b}$ ). Moreover, the TNAs and TNWs/TNAs degraded effectively and rapidly the five investigated antibiotics, obtained over 95\% removal at $20 \mathrm{~min}$ (Figure $4 \mathrm{a}, \mathrm{b}$ ). In Figure $4 \mathrm{~d}$, the k values were in the range of $0.14-0.36 \mathrm{~min}^{-1}$ for TNAs, and $0.15-0.38 \mathrm{~min}^{-1}$ for TNWs/TNAs. Specifically, the photocatalytic reaction rates of SMZ and SMX using TNAs and TNWs/TNAs under UV-VIS irradiation reached high values of $0.24-0.38 \mathrm{~min}^{-1}$, but they were only $0.14-0.16 \mathrm{~min}^{-1}$ for LCM, DXC, and OTC. This is primarily attributed to the differences in molecule structure and UV absorbance between the former and the latter. Indeed, SMZ and SMX have amine bond structures so that bond-breaking can easily occur between $-\mathrm{SO}_{2}$ - and its side atoms, and at $\mathrm{C}-\mathrm{S}$ and $\mathrm{N}-\mathrm{H}$ bonds under $\mathrm{UV}$ irradiation. Meanwhile, the imide bond structures $\left(\mathrm{RCONR}_{2}\right)$ of LCM, DXC, and OTC are generally photolyzed by 
the breaking of $\mathrm{R}-\mathrm{CO}$ or $\mathrm{CO}-\mathrm{N}$ bonds [80]. However, amides have the most stable of the carbonyl couplings due to their high resonance stabilization between the $\mathrm{N}-\mathrm{C}$ and $\mathrm{C}-\mathrm{O}$ bonds [80]. Therefore, amide bonds are highly resistant to photodegradation [80,81]. Besides the factor of molecule structure stability, UV absorbance also plays a role in that the antibiotics with higher UV absorbance had the higher k values (e.g., SMX, LCM, see Figure 4c,d). Furthermore, the k values of TNAs were slightly lower than those of TNWs/TNAs for LCM, DXC, OTC, SMZ, and SMX (Figure 4d). This could be primarily attributed to the larger surface area of TNWs/TNAs than that of TNAs, because the former had a layer TNWs with a length of $\sim 6 \mu \mathrm{m}$ partially covering the top of the TNAs (Figure $3 \mathrm{~b}$ ). This explanation is reasonable when TNAs had slightly larger grain size and greater crystallinity than TNWs/TNWs, factors that support better photocatalyst activity. The higher k value of TNWs/TNAs than TNAs is consistent with the results in [67], in which the film of the TNWs/TNAs exhibited 33-48\% higher photocatalytic activity than their corresponding pure TNAs. The present results are of great interest for further studies toward more effective treatment for antibiotic residues in aquaculture wastewater using $\mathrm{TiO}_{2}$ nanomaterials.
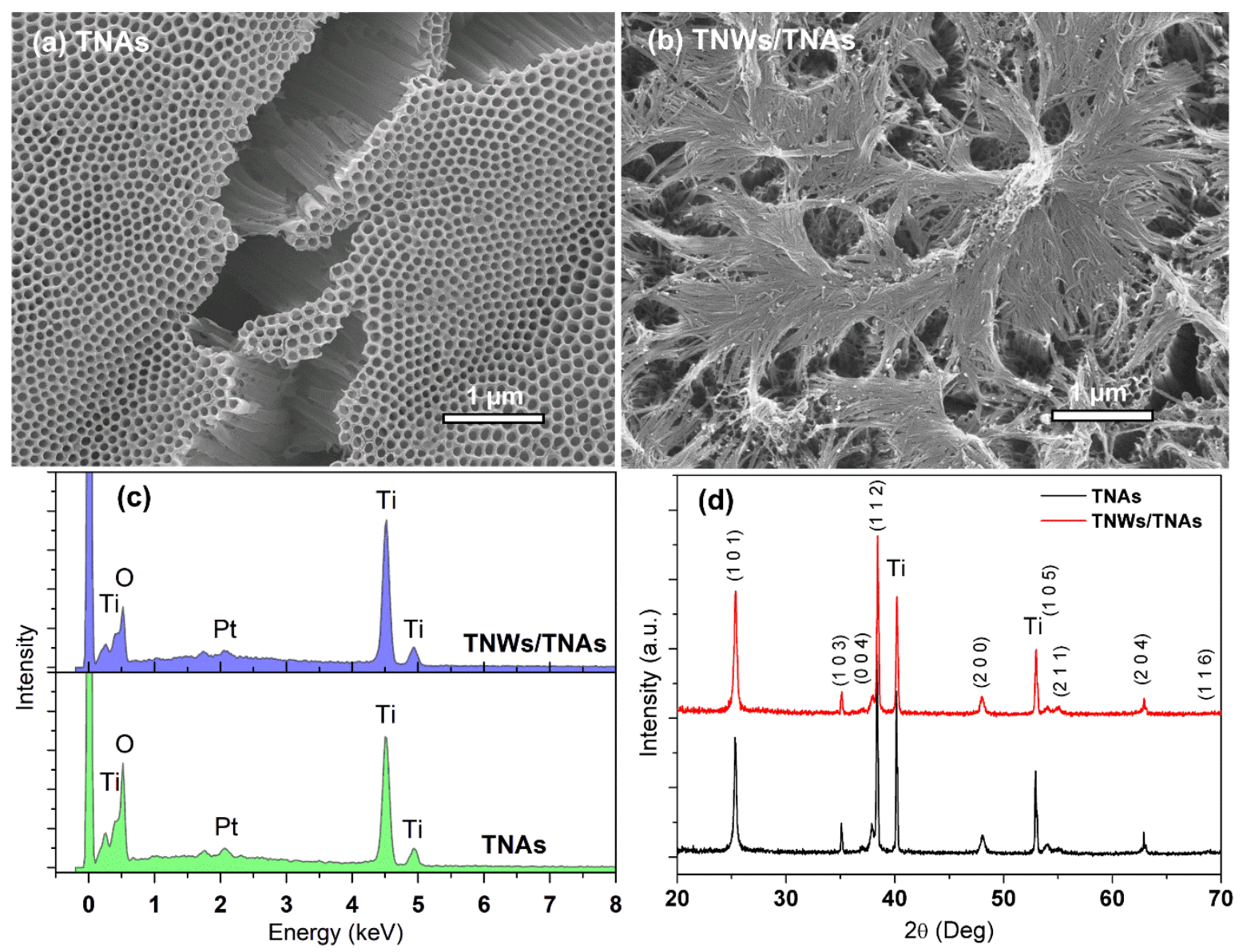

Figure 3. (a,b) Scanning electron microscopy (SEM) images of $\mathrm{TiO}_{2}$ nanotube arrays (TNAs) and $\mathrm{TiO}_{2}$ nanowires on TNAs (TNWs/TNAs). (c) Energy-dispersive X-ray spectroscopy (EDS) spectra of the TNAs and TNWs/TNAs. (d) X-ray diffraction (XRD) patterns of the TNAs and TNWs/TNAs. 

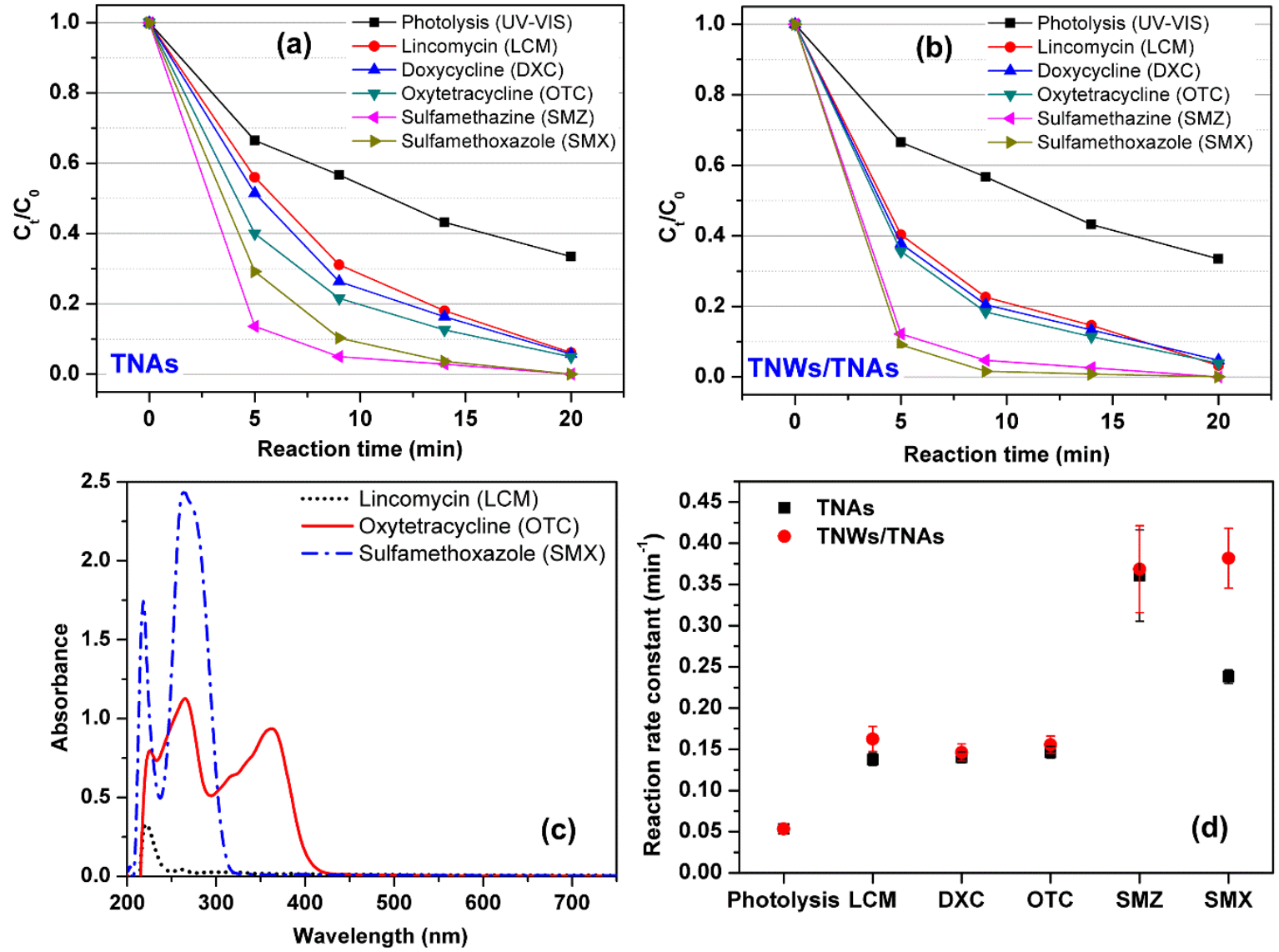

Figure 4. (a,b) Photocatalytic degradation of lincomycin (LCM), doxycycline (DXC), oxytetracycline (OTC), sulfamethazine (SMZ), and sulfamethoxazole (SMX) using TNAs and TNWs/TNAs under photolysis of UV-VIS irradiation $\left(120 \mathrm{~mW} / \mathrm{cm}^{2}\right)$. (c) Absorption spectrum of LCM, OTC, and SMX. (d) The photolysis and photocatalytic reaction rate constants of TNAs and TNWs/TNAs for the five different antibiotics.

\section{Materials and Methods}

\subsection{Chemicals and Reagents}

All reference standards of amoxicillin (AMOX) and ampicillin (AMPI); doxycycline (DXC) and oxytetracycline (OTC); lincomycin (LCM); vancomycin (VCM) and sulfamethazine (SMZ); sulfamethoxazole (SMX) and internal standards including trimethoprim (TMTP) and atenolol were purchased from Sigma-Aldrich (Saint Louis, MO, USA) with high purity grade ( $\geq 98.3 \%$ ). High-purity grade acetonitrile, methanol, water, and formic were supplied by Merck (Darmstadt, Germany). All solvents or chemicals for sample preparation and analysis at analytical grade was purchased from J.T. Baker (PA, USA). Disodium ethylene diamine tetraacetate $\left(\mathrm{Na}_{2} \mathrm{EDTA}\right.$, purity $\left.99 \%\right)$ was purchased from EMD Chemicals (Darmstadt, Germany). Ultra-pure water was obtained using a Milli- $Q^{R}$ ultra-pure water system (Millipore Corporation, Bedford, MA, USA). Individual standard solutions at a concentration of $1 \mathrm{mg} / \mathrm{mL}$ (stock solution) were prepared in water with $0.1 \%$ formic acid. The stock solutions were stored at $5{ }^{\circ} \mathrm{C}$ for a maximum of three weeks, and working solutions of the standard mixture of all pharmaceuticals were prepared by appropriate dilution of the individual stock solutions.

\subsection{Sample Collections}

Water samples were collected from four large-scale aquaculture areas of the Mekong Delta, Vietnam. They included ten aquaculture wastewater samples $\left(\mathrm{CM}-\mathrm{DD}^{1-10}\right)$ from four shrimp farms 
and a river-water sample collected at the Dam Doi River (DD-Riv) in Dam Doi district, Ca Mau province; ten wastewater samples from three shrimp farms $\left(\mathrm{BL}-\mathrm{HB}^{1-10}\right)$ and a river-water sample from Bac Lieu River (BL-Riv) in Hoa Binh district, Bac Lieu province; six wastewater samples (CT-TL ${ }^{1-6}$ ) from three pangasius farms and a water sample from Xeo Sao canal (XS-Cal) in Thoi Lai district, Can Tho city; nine wastewater samples from three pangasius farms (AG-CT ${ }^{1-9}$ ) and one water sample from Bon Tong canal (BT-Cal) in Chau Thanh district, An Giang province. Sampling sites are shown in Figure 5.

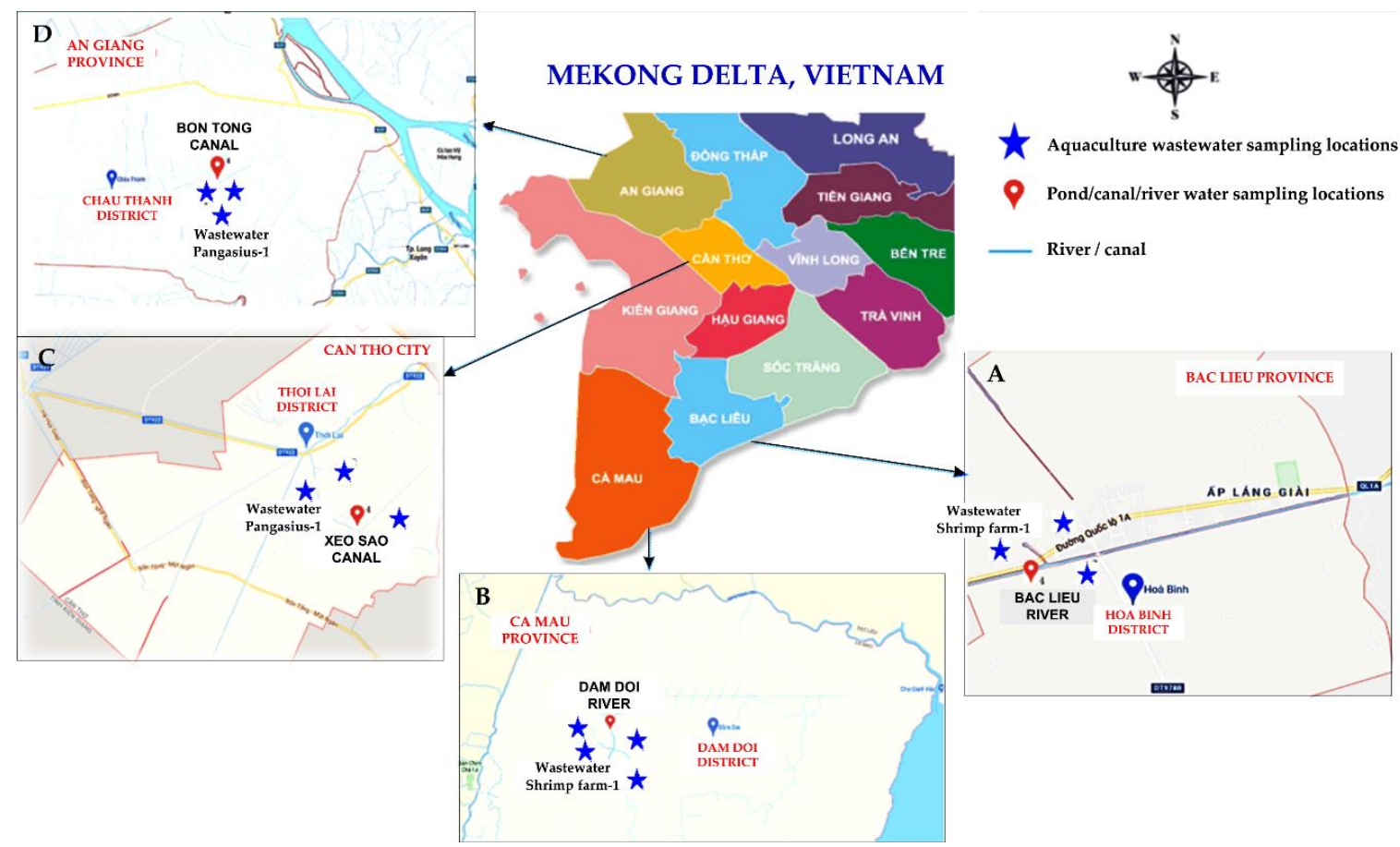

Figure 5. Sampling sites of aquaculture wastewaters and river/canal waters, collected from large-scale aquaculture areas of the Mekong Delta, Vietnam. A-Hoa Binh; B-Dam Doi; C-Thoi Lai; D-Chau Thanh district.

\subsection{Sample Pre-Treatment}

Water samples were collected in amber glass bottles, pre-rinsed with ultra-pure water, and used within $12 \mathrm{~h}$. $\mathrm{HCl} 0.1 \mathrm{M}$ was added into the sample to adjust the $\mathrm{pH}$ to 2.5 , and it was filtered through a $1-\mu \mathrm{m}$ glass fiber filter from Whatman (Maidstone, Kent, UK), followed by a $0.45-\mu \mathrm{m}$ nylon membrane filter. The sample was used as a blank sample (without target compounds). Thereafter, three types of extraction procedures were investigated toward high recovery yields of target compounds by spiking a standard mixture of analytes into the blank sample. For the first procedure, $\mathrm{Na}_{2} \mathrm{EDTA}$ with a concentration of $0.1-0.5 \%(\mathrm{~m} / \mathrm{v})$ was added to $100 \mathrm{~mL}$ of homogenized blank sample for the enabled complexes with inorganic compounds in all types of matrices. The second procedure was the use of SPE cartridges with Oasis HLB $(200 \mathrm{mg}, 6 \mathrm{~mL})$ from Waters or Strata X (200 mg, $6 \mathrm{~mL})$ from Phenomenex. The cartridges were conditioned with $5 \mathrm{~mL}$ methanol, followed by $5 \mathrm{~mL}$ Milli-Q water at a flow rate of $5 \mathrm{~mL} \cdot \mathrm{min}^{-1}$ for each run. The samples were loaded onto the cartridges at a flow rate of $3 \mathrm{~mL} \cdot \mathrm{min}^{-1}$ using an SPE-12 position vacuum manifold (Phenomenex, CA, USA). The Strata-X cartridges were washed with $3 \mathrm{~mL}$ of Milli-Q water at a flow rate of $3 \mathrm{~mL} \cdot \mathrm{min}^{-1}$ to remove possible interferences. The cartridges were dried in a vacuum for approximately $5 \mathrm{~min}$, then further eluted with $3 \mathrm{~mL}$ methanol at $1 \mathrm{~mL} \cdot \mathrm{min}^{-1}$, and finally eluted with $3 \mathrm{~mL}$ formic acid $2 \%$ in methanol. The Oasis HLB was washed with $3 \mathrm{~mL}$ formic acid $2 \%$ and eluted with $3 \mathrm{~mL}$ methanol, and then with 2 $\mathrm{mL} \mathrm{NH} \mathrm{OH}_{5} \%$ in methanol. The third procedure is a combination of the first and second sample 
preparation procedures, in which the optimum level of $\mathrm{Na}_{2}$ EDTA solution in the second procedure was first added into the blank sample, and the mixture was then loaded through the Oasis HLB or the Strata X column. The blank samples were created simultaneously to evaluate any carryover during SPE. To perform LC-MS/MS analysis, the eluates were evaporated under a gentle nitrogen stream and reconstituted with $1 \mathrm{~mL}$ water with $0.1 \%$ formic acid.

\subsection{Liquid Chromatography/Mass Spectrometry Analysis}

The assay was conducted on the Acquity UPLC H-Class system, which includes a quaternary solvent manager, sample manager-flow through needle, column heater module coupled with a triple quadrupole mass spectrometer, and Xevo TQD (Waters Corporation, Milford, MA, USA) equipped with an electrospray ionization (ESI) interface in multiple reaction monitoring (MRM) modes. The desolvation gas was nitrogen (purity 99.9\%). Masslynx 4.1 software was used to control the operation and data processing. Moreover, the IntelliStart tool of Masslynx 4.1 was utilized to optimize the MS/MS parameters, such as capillary, cone voltage, desolvation temperature, gas flow, collision potentials, and dwell time, by directly infusing standard solutions of each individual compound $\left(500 \mathrm{ng} \cdot \mathrm{mL}^{-1}\right)$ into the mass spectrometer to obtain the highest and most stable signal of precursor and fragment ions.

It is well established that most analytes are medium to polar compounds with pKa from 2 to $8[19,24,25,30,32]$. Hence, the reverse-phase chromatographic technique was selected suitably using acetonitrile, methanol, and water with or without adding $\mathrm{pH}$ modifier as the mobile phase. We investigated the influence factors for separation and peak shapes, including stationary phase, mobile phase (types, $\mathrm{pH}$, ratio, isocratic or gradient), flow rate, column temperature, and sample preparation.

\subsection{Method Validation}

Dynamic range was determined using calibration curves of matrix-matched solutions, prepared by spiking wastewater extraction at seven concentrations ranging from the quantification limit of each analyte to $200 \mathrm{ng} \cdot \mathrm{mL}^{-1}$. Each point was obtained from the mean of three injections and integrated peak area data. The selected quantification MRM transitions were used to construct matrix-matched calibration curves, which were used for quantitative determinations. Thereafter, the method detection limit (MDL) and method quantitation limit (MQL) were determined as the minimal concentration providing a chromatographic peak 3 or 10 times higher than the baseline noise from the spiked aquaculture wastewaters, respectively. Furthermore, the effects of different sample matrices on the accuracy of extraction recoveries were investigated by spiking blank samples of aquaculture wastewater with known amounts of the reference compounds, at three concentrations in six replicates of analyzing raw samples and treated wastewater samples. The recovery rate (in percentage) was obtained by comparing an experimental value to a theoretical one. Another important requirement of method validation is the repeatability that was deduced from relative standard deviations (\% RSD) for every compound from six replicates of spiked raw and treated wastewater samples, and the intermediate precision by assaying one sample in six times quintuplicate on day 1 . The same procedures were repeated on two more days, and the variation within one day (intra-day precision) and within three days (inter-day precision) was determined based on the peak area. However, the matrix effect on MS analysis was evaluated by subtracting the slope ratio between the matrix-matched standard curve and the standard solution curve and then multiplying by 100 to obtain the value in percentage. The signal is enhanced if the value is negative, whereas the signal is suppressed if the value is positive $[19,24-26,28]$.

\subsection{Fabricate of $\mathrm{NanoTiO}_{2}$ Materials}

Titanium (Ti) foil (99.9\% purity, size of $1 \mathrm{~cm} \times 2.5 \mathrm{~cm}$, thickness of $0.4 \mathrm{~mm}$ ) was used as the substrate for growing TNAs and TNWs/TNAs using the anodization method. Prior to anodization, Ti foil was ultrasonically cleaned in acetone, methanol, and deionized water (each solvent $10 \mathrm{~min}$ ) and then dried using a purging $\mathrm{N}_{2}$ gas. The anodization was carried out using a two-electrode system with the Ti foil as an anode and a stainless steel foil (SS304) as a cathode. All the electrolytes consisted of 
$0.3 \mathrm{wt} \% \mathrm{NH}_{4} \mathrm{~F}$ (SHOWA, Tokyo, Japan) in ethylene glycol solution with $2 \mathrm{vol} \%$ water. The foil was anodized at $30 \mathrm{~V}$ for $1 \mathrm{~h}$ and $5 \mathrm{~h}$ to grow TNAs and TNWs/TNAs, respectively. The samples were then annealed at $400{ }^{\circ} \mathrm{C}$ for $1 \mathrm{~h}$ to induce sample crystallization. The crystal structure of $\mathrm{TiO}_{2}$ nanomaterials was determined through X-ray diffraction (XRD; Bruker D2) using $\mathrm{CuK}_{\alpha}$ radiation $(\lambda=1.5406 \AA)$ in $2 \theta-\theta$ configuration. The surface morphology of the samples was examined using field-emission scanning electron microscopy (SEM, JEOL JSM-6500, Pleasanton, CA, USA). The compositions of the samples were analyzed through Oxford energy-dispersive X-ray spectroscopy (EDS) equipped with the SEM instrument at an accelerating voltage of $15 \mathrm{kV}$, dead time of $22-30 \%$, and collection time of $60 \mathrm{~s}$.

\subsection{Photocatalytic Reactions}

Photocatalytic reactions were carried out by immersing a sample into a $30 \mathrm{~mL}$ antibiotic solution of the selected environmental samples under UV-VIS at approximately $120 \mathrm{~mW} \cdot \mathrm{cm}^{-2}$ using a $100 \mathrm{~W}$ Xenon lamp. The photocatalytic reactor is a top-down irradiation system where the Xenon lamp is $16 \mathrm{~cm}$ above the solution container. Prior to illumination, the catalyst was immersed in the solution and magnetic stirring followed for $20 \mathrm{~min}$ in the dark, to ensure absorption-desorption equilibrium between the photocatalyst (sample) and antibiotic solution. The reaction temperature was kept at $32-33^{\circ} \mathrm{C}$ for all photocatalytic reactions. After a certain photocatalytic reaction time from 0 to $20 \mathrm{~min}$, qualitative and quantitative analysis of antibiotics was determined using the LC-MS/MS technique.

\section{Conclusions}

A simple, selective, sensitive, accurate, and reproducible LC-MS/MS method has been developed in this study for simultaneous quantitative and qualitative analysis of eight antibiotic residues in aquaculture and river water samples from the Mekong Delta, Vietnam. We used a Poroshell 120 Phenyl-Hexyl column $(4.6 \mathrm{~mm} ; 150 \mathrm{~mm} \times 2.7 \mu \mathrm{m})$, mobile phase in gradient mode containing acetonitrile-methanol-water with $0.1 \%$ formic acid, electrospray ionization in positive mode, and multi-reaction monitoring (MRM) transition for quantification. Solid-phase extraction was conducted on enriched samples. As a result, this assay was fully validated to meet the requirements, namely a wide linear range $\left(0.05-200 \mathrm{ng} \cdot \mathrm{mL}^{-1}\right)$, high correlation coefficient $\left(\mathrm{r}^{2}>0.995\right)$, good recovery $(87.03-105.6 \%)$, and intermediate precision (RSD $\leq 4.73 \%$ ). Method detection limits (MDLs) and method quantitation limits (MQLs) for the antibiotics were in the range of $0.01-0.07 \mathrm{ng} \cdot \mathrm{mL}^{-1}$ and 0.03-0.20 ng. $\mathrm{mL}^{-1}$, respectively. Doxycycline, sulfamethoxazole, oxytetracycline, lincomycin, and sulfamethazine were found with high proportions over $65 \%$ and high average concentrations between 22.6 and $76.8 \mathrm{ng} \cdot \mathrm{mL}^{-1}$, while ampicillin and amoxicillin appeared in lower portions below $8.6 \%$ and low average concentrations below $0.8 \mathrm{ng} \cdot \mathrm{mL}^{-1}$ in the aquaculture water samples. Although vancomycin is a banned antibiotic in aquaculture, it was still detected with a proportion of $23.1 \%$ at low concentrations. Furthermore, photocatalytic degradation of antibiotic residues in the aquaculture wastewater samples using $\mathrm{TiO}_{2}$ nanomaterials (i.e., TNAs and TNWs/TNAs) under $120 \mathrm{~mW} \cdot \mathrm{cm}^{-2} \mathrm{UV}-\mathrm{VIS}$ irradiation were studied. It is found that these nanomaterials were effective photocatalysts for the degradation of doxycycline, sulfamethoxazole, oxytetracycline, lincomycin, and sulfamethazine antibiotics. Herein, the combination of advanced analysis and treatment methods using nano-photocatalysts is promising to determine and degrade antibiotic residues in aquatic environments. Although TNAs and TNWs/TNAs exhibit promising photocatalytic activities, further investigations are needed toward more effective nanophotocatalysts in the degradation of antibiotics and other pollutants. The photocatalyst study part is as a further validation and an example of the application of the developed method.

Supplementary Materials: The following are available online at http://www.mdpi.com/2073-4344/10/3/356/s1, Figures S1-S10: Optimization of MS-MS parameters for antibiotic analysis; Figures S11-S14: Chromatograms indicated the effects of solvents on dissolve analytes; Figures S15-S16: Chromatograms indicated influence of mobile phase pH; Figures S17-S19: Chromatograms indicated influence of mobile phase types; Figures S20-S21: Chromatograms indicated influence of elution program; Figures S22-S25: Chromatograms present the investigation of sample preparation; Figures S26-S33: Method validation-Linearity of target antibiotics; Figures S34-S36: 
Method validation- LC-MS/MS chromatograms for specificity of target antibiotics; Figures S37-S41: LC-MS/MS chromatograms of analyzing aquaculture and river/canal water samples.

Author Contributions: D.Q.N. and T.C.M.V.D. performed the experiments and analyzed the data; P.H.L. prepared the $\mathrm{TiO}_{2}$ nanomaterials and supervised the photocatalytic reaction experiments; T.C.M.V.D. and P.H.L. wrote and edited the paper; T.D.N. edited the paper and supervised the experiments and analysis. All authors have read and agreed to the published version of the manuscript.

Funding: This research is funded by the Vietnam National Foundation for Science and Technology Development (NAFOSTED) under grant number 103.99-2016.75.

Conflicts of Interest: The authors declare no conflict of interest.

\section{References}

1. Gelband, H.; Miller-Petrie, M.; Pant, S.; Gandra, S.; Levinson, J.; Barter, D.; White, A.; Laxminarayan, R. The State of the World's Antibiotics 2015; Center for Disease Dynamics, Economics \& Policy: Washington, DC, USA, 2015; pp. 1-79.

2. European Centre for Disease Prevention and Control. Combating Resistance to Last-Line Antibiotics in the EU Still a Priority; Press Release: Brussels, Belgium, 2015; pp. 1-3.

3. Kummerer, K. Resistance in the environment. J. Antimicrob. Chemother. 2004, 54, 311-320. [CrossRef] [PubMed]

4. Martínez, J.L. Antibiotics and antibiotic resistance genes in natural environments. Science 2008, 321, 365-368. [CrossRef] [PubMed]

5. Thuy, H.T.T.; Nguyen, T.D. The potential environmental risks of pharmaceuticals in Vietnamese aquatic systems: Case study of antibiotics and synthetic hormones. Environ. Sci. Pollut. Res. 2013, $20,8132$. [CrossRef] [PubMed]

6. Jelic, A.; Petrovic, M.; Barcelo, D. Multi-residue method for trace level determination of pharmaceuticals in solid samples using pressurized liquid extraction followed by liquid chromatography/quadrupole-linear ion trap mass spectrometry. Talanta 2010, 80, 363-371. [CrossRef]

7. Leung, H.W.; Minh, B.T.; Murphy, M.B.; Lam, J.C.W.; So, M.K.; Martin, M.; Lam, P.K.S.; Richardson, B.J. Distribution, fate and risk assessment of antibiotics in sewage treatment plants in Hong Kong, South China. Environ. Int. 2012, 42, 1-9. [CrossRef]

8. Dasenaki, M.E.; Thomaidis, N.S. Multi analyte method for the determination of pharmaceuticals in wastewater samples using solid-phase extraction and liquid chromatography-tandem mass spectrometry. Anal. Bioanal. Chem. 2015, 407, 4229. [CrossRef]

9. Gago-Ferrero, P.; Borova, V.; Dasenaki, M.E.; Thomaidis, N.S. Simultaneous determination of 148 pharmaceuticals and illicit drugs in sewage sludge based on ultrasound-assisted extraction and liquid chromatography-tandem mass spectrometry. Anal. Bioanal. Chem. 2015, 407, 4287-4297. [CrossRef]

10. Wei, R.; Ge, F.; Huang, S.; Chen, M.; Wang, R. Occurrence of veterinary antibiotics in animal wastewater and surface water around farms in Jiangsu Province, China. Chemosphere 2011, 82, 1408-1414. [CrossRef]

11. Kolpin, D.W.; Furlong, E.T.; Meyer, M.T.; Thurman, E.M.; Zaugg, S.D.; Barber, L.B.; Buxton, H.T. Pharmaceuticals, hormones, and other organic wastewater contaminants in U.S. streams, 1999-2000: A national reconnaissance. Environ. Sci. Technol. 2002, 36, 1202-1211. [CrossRef]

12. European Commission. Directive 2000/60/EC of the European Parliament and of the council 23 October 2000 establishing a framework for community action in the field of water policy. Off. J. Eur. Commun. 2000, L327, $1-71$.

13. Vietnam Industrial Pollution Management Project (P113151). In Environmental and Social Management Framework; Ministry of Planning and Investment: Hanoi, Vietnam, 2015; pp. 29-58.

14. Ngo, T.T.; Le, N.T.; Hoang, T.M.; Luong, D.H. Water Scarcity in Vietnam: A Point of View on Virtual Water Perspective. Water Resour. Manag. 2018, 32, 3579. [CrossRef]

15. Wilder, M.; Nguyen, T.P. The Status of Aquaculture in the Mekong Delta Region of Vietnam: Sustainable Production and Combined Farming Systems. Fish. Sci. 2002, 68, 847-850. [CrossRef]

16. Binh, V.N.; Dang, N.; Anh, N.T.K.; Ky, L.X.; Thai, P.K. Antibiotics in the aquatic environment of Vietnam: Sources, concentrations, risk and control strategy. Chemosphere 2018, 197, 438-450. [CrossRef] [PubMed] 
17. Pham, T.T.H.; Rossi, P.; Dinh, H.D.K.; Pham, N.T.A.; Tran, P.A.; Ho, T.T.K.M.; Dinh, Q.T.; Alencastro, L.F.D. Analysis of antibiotic multi-resistant bacteria and resistance genes in the effluent of an intensive shrimp farm (Long An, Vietnam). J. Environ. Manag. 2018, 214, 149-156. [CrossRef]

18. Watkinson, A.J.; Murby, E.J.; Costanzo, S.D. Removal of antibiotics in conventional and advanced wastewater treatment: Implications for environmental discharge and wastewater recycling. Water Res. 2007, 41, 4164-4176. [CrossRef]

19. Li, B.; Zhang, T.; Xu, Z.; Fang, H.H.P. Rapid analysis of 21 antibiotics of multiple classes in municipal wastewater using ultra performance liquid chromatography-tandem mass spectrometry. Anal. Chim. Acta 2009, 645, 64-72. [CrossRef]

20. Opris, O.; Soran, M.-L.; Coman, V.; Copaciu, F.; Ristoiu, D. Determination of some frequently used antibiotics in waste waters using solid phase extraction followed by high performance liquid chromatography with diode array and mass spectrometry detection. Cent. Eur. J. Chem. 2013, 11, 1343-1351. [CrossRef]

21. Cha, J.; Yang, S.; Carlson, K.H. Occurrence of $\beta$-lactam and polyether ionophore antibiotics in surface water, urban wastewater, and sediment. Geosyst. Eng. 2015, 18, 140-150. [CrossRef]

22. Elhag, D.E.; Abdallah, B.S.; Hassan, M.; Suliman, A. Pharmaceutica ESI-LC/MS Method Development and Validation for the Determination of Some Selected Antibiotics in Hospital Wastewater. Pharm. Anal. Acta 2018, 9, 1-6.

23. Rossmann, J.; Schubert, S.; Gurke, R.; Oertel, R.; Kirch, W. Simultaneous determination of most prescribed antibiotics in multiple urban wastewater by SPE-LC-MS/MS. J. Chromatogr. B 2014, 969, 162-170. [CrossRef]

24. Shao, B.; Chen, D.; Zhang, J.; Wu, Y.; Sun, C. Determination of 76 pharmaceutical drugs by liquid chromatography-tandem mass spectrometry in slaughterhouse wastewater. J. Chromatogr. A 2009, 1216, 8312-8318. [CrossRef] [PubMed]

25. Lopez-Serna, R.; Perez, S.; Ginebreda, G.; Petrovic, M.; Barcelo, D. Fully automated determination of 74 pharmaceuticals in environmental and waste waters by online solid phase extraction-liquid chromatography-electrospray-tandem mass spectrometry. Talanta 2010, 83, 410-424. [CrossRef] [PubMed]

26. Yang, S.; Carlson, K.H. Solid-phase extraction-high-performance liquid chromatography-ion trap mass spectrometry for analysis of trace concentrations of macrolide antibiotics in natural and waste water matrices. J. Chromatogr. A 2004, 1038, 141-155. [CrossRef] [PubMed]

27. Mirzaei, R.; Yunesian, M.; Nasseri, S.; Gholam, M.; Jalilzadeh, E.; Shoeibi, S.; Bidshahi, H.S.; Mesdaghinia, A. An optimized SPE-LC-MS/MS method for antibiotics residue analysis in ground, surface and treated water samples by response surface methodology- central composite design. J. Environ. Health Sci. Eng. 2017, 5, 21. [CrossRef]

28. Pailler, J.-Y.; Krein, A.; Pfiste, L.; Hoffmann, L.; Guignard, C. Solid phase extraction coupled to liquid chromatography-tandem mass spectrometry analysis of sulfonamides, tetracyclines, analgesics and hormones in surface water and wastewater in Luxembourg. Sci. Total Environ. 2009, 407, 4736-4743. [CrossRef]

29. Miao, X.-S.; Bishay, F.; Chen, M.; Metcalfe, C.D. Occurrence of Antimicrobials in the Final Effluents of Wastewater Treatment Plants in Canada. Environ. Sci. Technol. 2004, 38, 3533-3541. [CrossRef]

30. Batt, L.A.; Aga, S.D. Simultaneous Analysis of Multiple Classes of Antibiotics by Ion Trap LC/MS/MS for Assessing Surface Water and Groundwater Contamination. Anal. Chem. 2005, 77, 2940-2947. [CrossRef]

31. Yang, S.; Cha, J.; Carlson, K. Quantitative determination of trace concentrations of tetracycline and sulfonamide antibiotics in surface water using solid-phase extraction and liquid chromatography/ion trap tandem mass spectrometry. Rapid Commun. Mass Spectrom. 2004, 18, 2131-2145. [CrossRef]

32. Babic, S.; Pavlović, D.M.; Ašperger, D.; Periša, M.; Zrnčić, M.; Horvat, A.J.M.; Kaštelan-Macan, M. Determination of multi-class pharmaceuticals in wastewater by liquid chromatography-Tandem mass spectrometry (LC-MS-MS). Anal. Bioanal. Chem. 2010, 398, 1185-1194. [CrossRef]

33. Zuccato, E.; Castiglioni, S.; Fanelli, R. Identification of the pharmaceuticals for human use contaminating the Italian aquatic environment. J. Hazzard. Mater. 2005, 122, 205-209. [CrossRef]

34. Xu, W.-H.; Zhang, G.; Zou, S.-C.; Li, X.-D.; Liu, Y.-C. Determination of selected antibiotics in the Victoria Harbour and the Pearl River, South China using high-performance liquid chromatography-electrospray ionization tandem mass spectrometry. Environ. Pollut. 2007, 145, 672-679. [CrossRef] [PubMed]

35. Managaki, S.; Murata, A.; Takada, H.; Tuyen, B.C.; Chiem, N.H. Distribution of macrolides, sulfonamides, and trimethoprim in tropical waters: Ubiquitous occurrence of veterinary antibiotics in the Mekong Delta. Environ. Sci. Technol. 2007, 41, 8004-8010. [CrossRef] [PubMed] 
36. Giang, C.N.D.; Sebesvari, Z.; Renaud, F.; Rosendahl, I.; Minh, Q.H.; Amelung, W. Occurrence and dissipation of the antibiotics sulfamethoxazole, sulfadiazine, trimethoprim, and enrofloxacin in the Mekong Delta, Vietnam. PLOS ONE 2015, 10, e0131855.

37. Hoa, P.T.P.; Managaki, S.; Nakada, N.; Takada, H.; Shimizu, A.; Anh, D.H.; Viet, P.H.; Suzuki, S. Antibiotic contamination and occurrence of antibiotic-resistant bacteria in aquatic environments of northern Vietnam. Sci. Total Environ. 2011, 409, 2894-2901. [CrossRef]

38. Castiglioni, S.; Bagnati, R.; Calamari, D.; Fanelli, R.; Zuccato, E. A multiresidue analytical method using solid-phase extraction and high-pressure liquid chromatography tandem mass spectrometry to measure pharmaceuticals of different therapeutic classes in urban wastewaters. J. Chromatogr. A 2005, 1092, 206-215. [CrossRef]

39. Kasprzyk-Hordern, B.; Dinsdale, R.M.; Guwy, A.J. Multi-residue method for the determination of basic/neutral pharmaceuticals and illicit drugs in surface water by solid-phase extraction and ultra-performance liquid chromatography-positive electrospray ionisation tandem mass spectrometry. J. Chromatogr. A 2007, 1161, 132-145. [CrossRef]

40. Teixeira, S.; Gurke, R.; Eckert, H.; Kuhn, K.; Fauler, J.; Cuniberti, G. Photocatalytic degradation of pharmaceuticals present in conventional treated wastewater by nanoparticle suspensions. J. Environ. Chem. Eng. 2016, 4, 287-292. [CrossRef]

41. Russo, D.; Cochran, K.H.; Westerman, D.; Puma, G.L.; Marotta, R.; Andreozzi, R.; Richardson, S.D. Ultrafast photodegradation of isoxazole and isothiazolinones by $\mathrm{UV} 254$ and $\mathrm{UV} 254 / \mathrm{H}_{2} \mathrm{O}_{2}$ photolysis in a microcapillary reactor. Water Res. 2020, 169, 115203. [CrossRef]

42. Wang, J.; Wang, S. Removal of pharmaceuticals and personal care products (PPCPs) from wastewater: A review. J. Environ. Manag. 2016, 182, 620-640. [CrossRef]

43. Russo, D.; Tammaro, M.; Salluzzo, A.; Andreozzi, R.; Marotta, R. Modeling and validation of a modular multi-lamp photo-reactor for cetylpyridinium chloride degradation by $\mathrm{UV}$ and $\mathrm{UV} / \mathrm{H}_{2} \mathrm{O}_{2}$ processes. Chem. Eng. J. 2019, 376, 120380. [CrossRef]

44. Pal, P. Treatment and Disposal of Pharmaceutical Wastewater: Towards Sustainable Strategy. Sep. Purif. Rev. 2017, 47, 179-198. [CrossRef]

45. Tiwari, B.; Sellamuthu, B.; Ouarda, Y.; Drogui, P.; Tyagi, R.D.; Buelna, G. Review on Fate and Mechanism of removal of pharmaceutical pollutants from wastewater using biological approach. Bioresour Technol. 2017, 224, 1-12. [CrossRef] [PubMed]

46. Klavarioti, M.; Mantzavinos, D.; Kassinos, D. Removal of residual pharmaceuticals from aqueous systems by advanced oxidation processes. Environ. Int. 2009, 35, 402-417. [CrossRef] [PubMed]

47. Andreozzi, R.; Caprio, V.; Insola, A.; Marotta, R. Advanced oxidation processes (AOP) for water purification and recovery. Catal. Today 1999, 53, 51-59. [CrossRef]

48. Siciliano, A.; Russo, D.; Spasiano, D.; Marotta, R.; Race, M.; Fabbricino, M.; Galdiero, E.; Guida, M. Chronic toxicity of treated and untreated aqueous solutions containing imidazole-based ionic liquids and their oxydized by-products. Ecotoxicol. Environ. Saf. 2019, 180, 466-472.

49. Babu, D.S.; Srivastava, V.; Nidheesh, P.V.; Kumar, M.S. Detoxification of water and wastewater by advanced oxidation processes. Sci. Total Environ. 2019, 696, 133961. [CrossRef]

50. Russo, D.; Siciliano, A.; Guida, M.; Andreozzi, R.; Reis, N.M.; Puma, G.L.; Marotta, R. Removal of antiretroviral drugs stavudine and zidovudine in water under UV254 and UV254/ $\mathrm{H}_{2} \mathrm{O}_{2}$ processes: Quantum yields, kinetics and ecotoxicology assessment. J. Hazard. Mater. 2018, 349, 195-204. [CrossRef]

51. Sharma, A.; Ahmad, J.; Flora, S.J.S. Application of advanced oxidation processes and toxicity assessment of transformation products. Environ. Res. 2018, 167, 223-233. [CrossRef]

52. Lucchetti, R.; Siciliano, A.; Clarizia, L.; Russo, D.; Somma, H.D.; Natale, F.D.; Guida, M.; Andreozzi, R.; Marotta, R. Sacrificial photocatalysis: Removal of nitrate and hydrogen production by nano-copper-loaded P25 titania. A kinetic and ecotoxicological assessment. Environ. Sci. Pollut. Res. 2017, 24, 5898-5907. [CrossRef]

53. Alharbi, S.K.; Price, W.E. Degradation and Fate of Pharmaceutically Active Contaminants by Advanced Oxidation Processes. Curr. Pollut. Rep. 2017, 3, 268-280. [CrossRef]

54. Hoffmann, M.R.; Martin, S.T.; Choi, W.; Bahnemann, D.W. Environmental Applications of Semiconductor Photocatalysis. Chem. Rev. 1995, 95, 69-96. [CrossRef] 
55. Lin, Z.; Ye, M.; Wang, M. Multifunctional Photocatalytic Materials for Energy; Woodhead Publishing in Materials: Cambridge, MA, USA, 2018; pp. 187-213.

56. Zhu, D.; Zhou, Q. Environmental Nanotechnology, Monitoring \& Management Action and mechanism of semiconductor photocatalysis on degradation of organic pollutants in water treatment: A review. Environ. Nanotechnol. Monit. Manag. 2019, 12, 100255.

57. Deng, Y.; Zhao, R. Advanced Oxidation Processes (AOPs) in Wastewater Treatment. Curr. Pollut. Rep. 2015, 1, 167-176. [CrossRef]

58. O'Shea, K.E.; Dionysiou, D.D. Advanced Oxidation Processes for Water Treatment. J. Phys. Chem. Lett. 2012, 3, 2112-2113. [CrossRef]

59. Stefan, M.I. Advanced Oxidation Processes for Water Treatment: Fundamental and Applications; IWA Publishing: London, UK, 2017; pp. 1-710.

60. Miranda-García, N.; Suárez, S.; Sánchez, B.; Coronado, J.M.; Malato, S.; Maldonado, M.I. Photocatalytic degradation of emerging contaminants in municipal wastewater treatment plant effluents using immobilized $\mathrm{TiO}_{2}$ in a solar pilot plant. Appl. Catal. B Environ. 2011, 103, 294-301. [CrossRef]

61. Hu, L.; Flanders, P.M.; Miller, P.L.; Strathmann, T.J. Oxidation of sulfamethoxazole and related antimicrobial agents by $\mathrm{TiO}_{2}$ photocatalysis. Water Res. 2007, 41, 2612-2626. [CrossRef]

62. Li, D.; Shi, W. Recent developments in visible-Light photocatalytic degradation of antibiotics. Chin. J. Catal. 2016, 37, 792-798. [CrossRef]

63. Le, P.H.; Hieu, L.T.; Lam, T.-N.; Hang, N.T.N.; Truong, N.V.; Tuyen, L.T.C.; Phong, P.T.; Leu, J. Enhanced Photocatalytic Performance of Nitrogen-Doped $\mathrm{TiO}_{2}$ Nanotube Arrays Using a Simple Annealing Process. Micromachines 2018, 9, 618. [CrossRef]

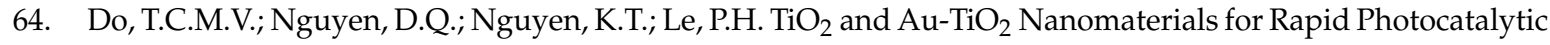
Degradation of Antibiotic Residues in Aquaculture Wastewater. Materials 2019, 12, 2434. [CrossRef]

65. Huang, J.-Y.; Zhang, K.-Q.; Lai, Y. Fabrication, Modification, and Emerging Applications of $\mathrm{TiO}_{2} \mathrm{Nanotube}$ Arrays by Electrochemical Synthesis: A Review. Int. J. Photoenergy 2013, 2013, 761971. [CrossRef]

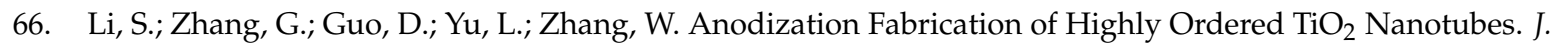
Phys. Chem. C 2009, 113, 12759-12765. [CrossRef]

67. Hsu, M.-Y.; Hsu, H.-L.; Leu, J. $\mathrm{TiO}_{2}$ Nanowires on Anodic $\mathrm{TiO}_{2}$ Nanotube Arrays (TNWs/TNAs): Formation Mechanism and Photocatalytic Performance. J. Electrochem. Soc. 2012, 159, H722-H727. [CrossRef]

68. MassBank Europe, High resolution Mass Spectral Database. Available online: https://massbank.eu/MassBank/ (accessed on 24 March 2020).

69. Hu, F.-Y.; He, L.-M.; Yang, J.-W.; Bian, K.; Wang, Z.-N.; Yang, H.-C.; Liu, Y.-H. Determination of 26 veterinary antibiotics residues in water matrices by lyophilization in combination with LC-MS/MS. J. Chromatogr. B 2014, 949-950, 79-86. [CrossRef] [PubMed]

70. Gros, M.; Rodríguez-Mozaz, S.; Barceló, D. Rapid analysis of multiclass antibiotic residues and some of their metabolites in hospital, urban wastewater and river water by ultra-high performance liquid chromatography coupled to quadrupole linear ion trap tandem mass spectrometry. J. Chromatogr. A 2013, 1292, 173-183. [CrossRef]

71. Minh, T.B.; Leung, H.W.; Loi, I.H.; Chan, W.H.; So, M.K.; Mao, J.Q.; Choi, D.; Lam, J.C.W.; Zheng, G.; Martin, M.; et al. Antibiotics in the Hong Kong metropolitan area: Ubiquitous distribution and fate in Victoria Harbour. Mar. Pollut. Bull. 2009, 58, 1052-1062. [CrossRef]

72. Shimizu, A.; Takada, H.; Koike, T.; Takeshita, A.; Saha, M.; Rinawati, N.; Murata, A.; Suzuki, T.; Suzuki, S.; Chiem, N.H.; et al. Ubiquitous occurrence of sulfonamides in tropical Asian waters. Sci. Total Environ. 2013, 452-453, 108-115. [CrossRef]

73. Zhang, T.; Watson, D.G.; Azike, C.; Tettey, J.N.A.; Stearns, A.T.; Binning, A.R.; Payne, C.J. Determination of vancomycin in serum by liquid chromatography-high resolution full scan mass spectrometry. J. Chromatogr. B 2007, 857, 352-356. [CrossRef]

74. Campagnolo, E.R.; Johnson, K.R.; Karpati, A.; Rubin, C.S.; Kolpin, D.W.; Meyer, M.T.; Esteban, J.E.; Currier, R.W.; Smith, K.; Thu, K.M.; et al. Antimicrobial residues in animal waste and water resources proximal to large-scale swine and poultry feeding operations. Sci. Total Environ. 2002, 299, 89-95. [CrossRef]

75. Tong, L.; Li, P.; Wang, Y.; Zhu, K. Analysis of veterinary antibiotic residues in swine wastewater and environmental water samples using optimized SPE-LC/MS/MS. Chemosphere 2009, 74, 1090-1097. [CrossRef] 
76. Commission Decision (2002/657/EC) of 12 August 2002 Implementing Council Directive 96/23/EC Concerning the Performance of Analytical Methods and the Interpretation of Results. Off. J. Eur. Commun. 2002, L221, $8-36$.

77. Thuy, T.T.H.; Nga, L.P.; Loan, T.T.C. Antibiotic contaminants in coastal wetlands from Vietnamese shrimp farming. Sci. Total Environ. 2011, 18, 835-841. [CrossRef]

78. Tuyen, L.T.C.; Jian, S.-R.; Tien, N.T.; Le, P.H. Nanomechanical and Material Properties of Fluorine-Doped Tin Oxide Thin Films Prepared by Ultrasonic Spray Pyrolysis: Effects of F-Doping. Materials 2019, 12, 1665. [CrossRef] [PubMed]

79. Sharma, S.D.; Saini, K.K.; Kant, C.; Sharma, C.P.; Jain, S.C. Photodegradation of dye pollutant under UV light by nano-catalyst doped titania thin films. Appl. Catal. B Environ. 2008, 84, 233-240. [CrossRef]

80. Kim, I.; Tanaka, H. Photodegradation characteristics of PPCPs in water with UV treatment. Environ. Int. 2009, 35, 793-802. [CrossRef] [PubMed]

81. Hu, A.; Zhang, X.; Luong, D.; Oakes, K.D.; Servos, M.R.; Liang, R.; Kurdi, S.; Peng, P.; Zhou, Y. Adsorption and photocatalytic degradation kinetics of pharmaceuticals by $\mathrm{TiO}_{2}$ nanowires during water treatment. Waste Biomass Valor. 2012, 3, 443-449. [CrossRef]

(C) 2020 by the authors. Licensee MDPI, Basel, Switzerland. This article is an open access article distributed under the terms and conditions of the Creative Commons Attribution (CC BY) license (http://creativecommons.org/licenses/by/4.0/). 